\title{
Working Time, Employment, and Work Sharing* Evidence from Sweden
}

\author{
Tor Jacobson \\ Stockholm School of Economics, Sweden \\ Henry Ohlsson \\ Uppsala University, Sweden
}

November 1996

\begin{abstract}
We study three necessary conditions for work sharing to increase employment. First, there must exist a negative long-run relation between working time and employment. Second, hours per worker must be exogenous with respect to wages and employment. Third, policy makers must be able to influence actual hours per worker. We formulate a theoretical model for employment, hours per worker, production, and real wages. A VAR system with cointegrating constraints is estimated by maximum likelihood using Swedish private sector data 1970:1-1990:4. We find (i) no long-run relation between hours per worker and employment, (ii) that hours per worker are endogenous with respect to the estimation of long-run parameters, and (iii) that legislated working time and hours per worker are related to each other in the long run.
\end{abstract}

KEYWORDS: work sharing, maximum likelihood cointegration, employment, hours per worker, real wages.

JEL Classification Numbers: E24, J22, J23.

Correspondence to: Tor Jacobson, Department of Economic Statistics, Stockholm School of Economics, Box 6501, 11383 Stockholm, Sweden, voice +46 873692 41, email stTJ@HнS.SE or Henry Ohlsson, Department of Economics, Uppsala University, Box 513, S-751 20 Uppsala, Sweden, voice +46 181810 96, fax +46 181814 78, email HENRY.oHLSSON@NEK.UU.SE .

*Financial support from Tore Browalds Forskningsstiftelse is gratefully acknowledged. We would like to thank Jonas Agell, Anders Forslund, Anders Vredin, Anders Warne, and participants at the 1995 EALE meeting in Lyon for helpful comments. 


\section{Introduction}

The worsening of the labour market conditions in Sweden during the beginning of the 1990s has meant that work sharing proponents have started to make their voices heard in the popular discussion and in Parliament. Sweden has caught up with European unemployment levels and, therefore, also with the popular work sharing discussion of the rest of Europe. With the high unemployment levels, any proposals claiming to mitigate the employment problems must be taken seriously. ${ }^{1}$ We argue that at least three conditions must be fulfilled for using work sharing as a policy instrument to increase employment. The objective of the paper is to shed light on the three related questions:

1. Is there a negative long-run trade-off between hours per worker and employment? The work sharing proponents have in mind a trade-off relation between hours per worker and employment. Reducing hours per worker will permit an expansion of employment. Analyses of the short-run implications of changes in hours per worker for labour demand cannot shed light on this issue if the objective of work sharing is to permanently increase employment. $^{2}$

Why a long-run relation and not a short-run? It is clear that the work sharing proponents have a long-run argument. Firms choose overtime rather than more employees in the short run, because the additional costs of overtime are lower than the hiring costs. In other words, the adjustment costs for employment are higher than those for hours per worker. The work sharing proponents are, of course, aware of this. To take their argument seriously we will have to regard the proposals as building on the idea of a more long term relations. We will, therefore, in the empirical analysis test if employment and hours per worker are governed by a common stochastic trend. When testing this it is important to take simultaneous effects on wages and production into account. If there is a common stochastic trend it implies that there is a stationary long-run relationship between the two. But it is also necessary for work sharing that the long-run relation implies a negative (trade-off) relation.

2. Are actual hours per worker exogenous in the long run? A negative longrun trade-off between hours per worker and employment is not sufficient to provide a basis for a work sharing policy. It is also necessary that hours per

\footnotetext{
${ }^{1}$ Houpis (1993) is a recent paper discussing work sharing.

${ }^{2}$ The specification of labor services is a theoretical and empirical topic in the recent real business cycle literature (Kydland, 1995). This literature is, however, more focused on the short-run fluctuations of the labor services variables.
} 
worker are exogenous with respect to employment, wages, and production. But exogeneity, in a general sense, does not lend itself to empirical testing. However, we can, within our framework, test if the changes in hours per worker are weakly exogenous with respect to the estimation of the parameters that govern the long-run relationship between employment and hours per worker. Weak exogeneity is necessary, but not sufficient, for hours per worker to be a policy instrument.

The second question has to do with causality. From a factor demand perspective, it is possible to view the working time (and the real wage) as given. But is it self-evident to view hours per worker as given from the household's perspective? This reduces factor supply to a question of labour force participation. But if labour supply (hours per worker) depends on the real wage, a correlation (and a causality) between hours and real wage is introduced. ${ }^{3}$ There is an extensive literature on the determinants of labour supply. The results found within this field must also be taken seriously.

3. Can actual hours in the long run be controlled by instruments available to policy makers? Politicians cannot directly decide on actual hours per worker. Instead they have to rely on working time legislation. But is this legislation in reality a restriction on the other agents in the economy? It is, e.g., possible that hours per worker (or the long-run trend for hours per worker) can be the result of bargaining between employers and workers rather than governed by the legislation. If this is the case working time legislation is not a potent policy tool.

We study a small system comprising the following variables: real production, $Y_{t}$, real wages, $W_{t}$, hours per worker, $H_{t}$, and employment, $N_{t}$. All variables concern the private sector in Sweden, 1970:1-1990:4. There are unfortunately no quarterly production and real wage data available before 1970. Because of the severe recession during 1991-1993, we only extend the sample period through 1990.

Our choice of statistical model has been guided by the following considerations. First, there are no strong theoretical justifications for claiming that any one of the four variables is exogenous with respect to any other. Second, massive empirical evidence suggest that macroeconomic variables such as $Y_{t}$ and $W_{t}$ are best modelled when unit roots are accounted for, i.e., when allowing for first order integration and, possibly, cointegration. Taken together, these two points

\footnotetext{
${ }^{3}$ Whitley and Wilson (1988) discuss the need to use simultaneous models when analysing work sharing, e.g., to capture both demand and supply factors.
} 
lead us to a VAR model with cointegration constraints as our method of empirical enquiry.

We specify a theoretical model which will enhance interpretation of the empirical results and serve as a basis for hypothesis testing. One use of the model is to retrieve economic parameters from the estimated reduced form coefficients in the empirical cointegrating vectors. Thus, the theoretical model should not be seen as a restriction for the empirical analysis. ${ }^{4}$

There are other possible links between employment and hours per than those emphasized here. It has, e.g., been claimed that welfare states, such as the Scandinavian countries, have experienced a reduction in hours per worker as the result of high marginal income taxes. However, it is also true that these countries encourage labour force participation through work fare elements in many welfare programs (Freeman, 1995). Workfare is not captured by our model.

Figures 1.1 and 1.2 present some stylized facts about the evolvement of the private sector labour market in Sweden during the last decades. Hours per worker and employment seem to exhibit slight downward trends during the 1970s. The 1980s reversed the trends, at least for hours per worker. Figure 1.1 does not support a negative long-run trade-off between hours per worker and employment. But there could still exist such a relationship controlling for the development of production and real wages. These variables show strong upward trends, with a greater volatility in real wages.

Our results are, first, that there is no long-run relationship between hours per worker and employment. Second, the data are not consistent with hours per worker being exogenous. Third, (actual) hours per worker and legislated hours per worker are related in the long-run. Our interpretation is that employment is not affected by hours per worker. The results are, in other words, in contrast the beliefs of work sharing proponents.

The paper is organized as follows: Section 2 gives the background by discussing the theoretical framework. (Some of the theoretical discussion is in Appendix A.) Section 3 presents the empirical results when studying the first two questions, while Section 4 extends the analysis to include legislated working time. Section 5 summarizes our main findings. Some additional information about the data can be found in the Appendix B.

\section{Theoretical framework}

In this section we will present a stylized private sector labour market model. The purpose of the model is to provide a simple, theoretical framework for interpre-

\footnotetext{
${ }^{4}$ Jacobson, Vredin and Warne (1996) use a similar approach when studying hysteresis effects in Scandinavian labor markets.
} 
Figure 1.1: Hours per worker and employment, logarithms, seasonally adjusted deviations from means.

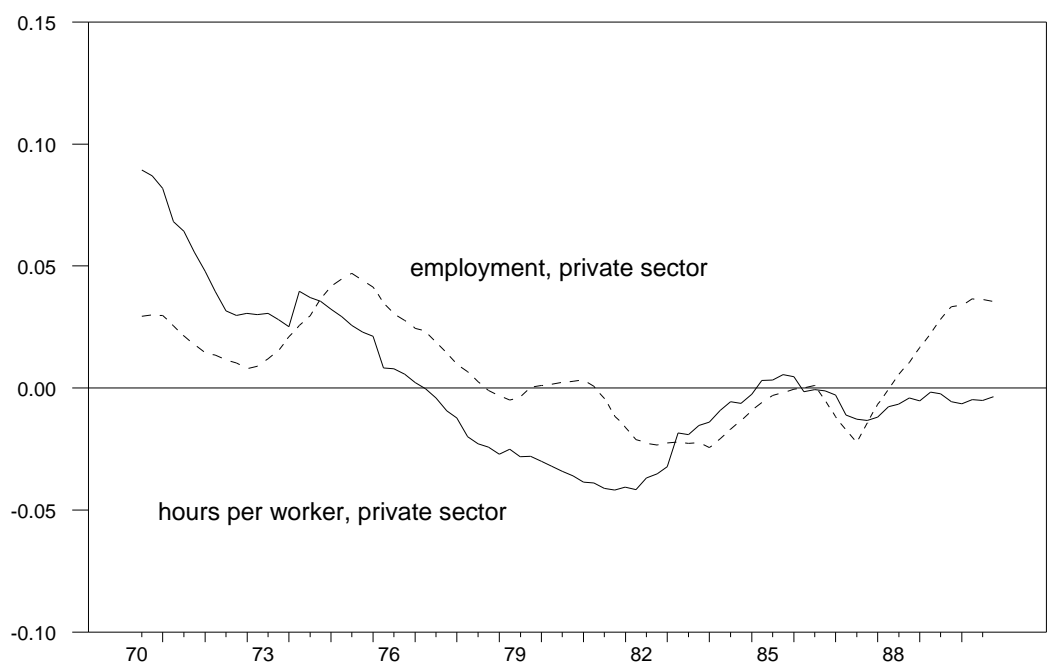

Figure 1.2: Production and real wage, logarithms, seasonally adjusted deviations from means.

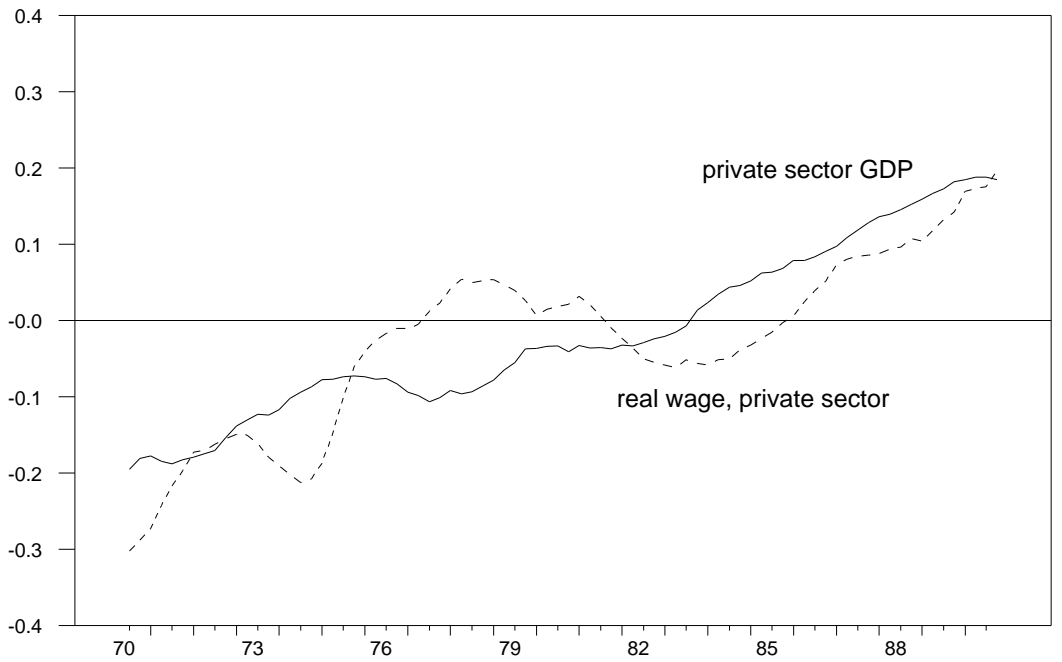


tation and a basis for hypotheses testing. The model is not a restriction for the empirical estimations. We will first present a deterministic version of the model explaining the economic content. We then specify a stochastic version which will permit linking with and interpretation of the empirical model.

There are three optimizing agents in the model: a representative firm, identical households, and a union. The decision variables of the profit maximizing firm are production and employment. In some specifications we allow a utility maximizing household to decide on hours worked by the single worker of the household. The union manipulates wages to maximize union utility.

\subsection{A deterministic version of the model}

Production and labour demand. We assume that the production function is:

$$
Y_{t}=\theta_{t}^{*} H_{t}^{\delta} N_{t}^{\rho}
$$

where $\theta_{t}^{*}$ is an exogenous labour productivity variable, $\delta$ is the output elasticity with respect to hours per worker $\left(H_{t}\right)$ while $\rho$ is the output elasticity with respect to employment $\left(N_{t}\right)$. We assume that $0<\delta, \rho<1$. If $\delta=\rho$ then changes on the intensive margin (hours per worker) and changes on the extensive margin (employment) are perfect technical substitutes, and the value of $\delta$ (or $\rho$ ) gives returns to scale. Production will in this special case only depend on the total number of hours. Changes in employment and hours per worker will not affect production as long as total hours are the same. Maximizing profits, assuming that employment is the only choice variable for the firm, yields the labour demand:

$$
N_{t}=\left(\rho \theta_{t}^{*}\right)^{\frac{1}{1-\rho}} W_{t}^{-\frac{1}{1-\rho}} H_{t}^{-\frac{1-\delta}{1-\rho}}
$$

where $W_{t}$ is the real product wage. Note that the wage-share, $\frac{W_{t} H_{t} N_{t}}{\theta_{t}^{*} H_{t}^{\delta} N_{t}^{\rho}}$, implied by the above is equal to $\rho$, i.e. the output elasticity with respect to employment. The elasticity of employment with respect to hours, holding production and wages constant, is -1 . There is, in other words, a one-to-one trade-off between hours per worker and employment.

However, using (2.2), we can incorporate the effect on output, and the employment elasticity with respect to hours - for given wages - becomes $-\frac{1-\delta}{1-\rho}$, which is negative by assumption. The elasticity of employment with respect to hours per worker will be $\gtrless-1$ depending on whether $\rho \gtrless \delta$. If output is more elastic with respect to employment than with respect to hours, a decrease in hours will increase employment proportionally more. Moreover, an increase in labour productivity $\theta_{t}^{*}$ will increase employment.

These relationships between hours and employment are from a factor demand perspective. But how about the impact of hours on wages and, consequently, on 
employment? To answer this question we need to say something about labour supply (hours per worker) and wage setting.

Exogenous hours per worker. Suppose that hours per worker are exogenously determined, e.g., by legislation. Let $\overline{H_{t}}$ represent hours per worker if exogenous. The exogenous hours per worker can simply be substituted in to (2.2) to obtain labour demand.

Wage setting. Suppose that wages are set by a union. The union maximizes the expected union utility of the income of a representative member. Unemployment is determined by random draw and the utility level for the unemployed is exogenous. The union utility function can be approximated by:

$$
U_{t}=N_{t}-L F_{t}+\left(\tau_{t}^{*} W_{t} \overline{H_{t}}\right)^{\lambda}
$$

where $L F_{t}$ is the labour force, i.e., the number of households, and $\lambda$ is a union preference parameter such that $0<\lambda<1$. Appendix A presents the approximation. When hours per worker are exogenous, union utility is maximized subject to the labour demand function (2.2). The resulting wage setting relation is:

$$
W_{t}=\Gamma_{0}^{*}\left(\rho \theta_{t}^{*}\right)^{\frac{1}{1+\lambda(1-\rho)}}\left(\tau_{t}^{*}\right)^{-\frac{\lambda(1-\rho)}{1+\lambda(1-\rho)}}\left(\overline{H_{t}}\right)^{-\frac{1-\delta+\lambda(1-\rho)}{1+\lambda(1-\rho)}} .
$$

where $\Gamma_{0}^{*}=\left(\frac{1}{(1-\rho) \lambda}\right)^{\frac{1-\rho}{1+\lambda(1-\rho)}}$. Decreasing hours per worker will increase the real wage. Higher labour productivity (higher $\theta_{t}^{*}$ ) will also increase the real wage, while a tax decrease (higher $\tau_{t}^{*}$ ) will lead to a lower real product wage. The real consumer wage will, on the other hand, increase. To get the employment effect, substitute (2.4) in to equation (2.2):

$$
N_{t}=\Gamma_{1}^{*}\left(\rho \theta_{t}^{*} \tau_{t}^{*}\right)^{\frac{\lambda}{1+\lambda(1-\rho)}}\left(\overline{H_{t}}\right)^{\frac{\delta \lambda}{1+\lambda(1-\rho)}} .
$$

where $\Gamma_{1}^{*}$ is a constant. The direct employment increasing effect of a reduction in hours per worker will be more than counteracted by the indirect effect of increased real wages as the employment elasticity with respect to hours is $\frac{\delta \lambda}{1+\lambda(1-\rho)}$. Higher labour productivity (contrary to the beliefs of some) will increase employment, and so will lower taxes .

Endogenous labour supply (hours per worker). Suppose instead that the individual household maximizes a utility function giving rise to a labour supply function which we assume can be approximated by:

$$
H_{t}=\left(\tau_{t}^{*} W_{t}\right)^{\eta}
$$

where $\tau_{t}^{*} W_{t}$ is the real consumption wage and $\tau_{t}^{*}$ is an exogenous price/tax-wedge variable. Increasing taxes will decrease $\tau_{t}^{*}$. The labour supply elasticity $\eta$ may 
be positive or negative depending on whether the substitution effects in absolute value is bigger or smaller than the income effect. Making hours endogenous, in a sense, reverses the causation between wages and hours. Computing the effect of wages, taking labour supply into account, can be done substituting (2.6) in to (2.2) to get:

$$
N_{t}=\left(\rho \theta_{t}^{*}\right)^{\frac{1}{1-\rho}}\left(\tau_{t}^{*}\right)^{-\frac{\eta(1-\delta)}{1-\rho}} W_{t}^{-\frac{1+\eta(1-\delta)}{1-\rho}} .
$$

Higher labour productivity $\theta_{t}^{*}$, for a given real wage, will increase employment. If the labour supply elasticity is positive (the substitution effect dominates), lower taxes (higher $\tau_{t}^{*}$ ) will decrease employment. Increases in the real wage will decrease employment if $1+\eta(1-\delta)>0$. A sufficient, but not necessary, condition for this is that the labour supply elasticity is positive.

Wage setting. When the labour supply is endogenous union utility is maximized subject to the labour supply function (2.6) and the labour demand function (2.7). The resulting wage setting relation is:

$$
W_{t}=\Gamma_{0}^{*}\left(\rho \theta_{t}^{*}\right)^{\frac{1}{\gamma}}\left(\tau_{t}^{*}\right)^{-\frac{\gamma-1}{\gamma}}
$$

where $\gamma=(\eta+1)(1+\lambda(1-\rho))-\eta \delta$ and $\Gamma_{0}^{*}=\left(\frac{1+\eta(1-\delta)}{(1-\rho)(\eta+1) \lambda}\right)^{\frac{1-\rho}{\gamma}}$. A positive labour supply elasticity is sufficient for higher labour productivity $\theta_{t}^{*}$ to increase the real wage. Lower taxes, so that $\tau_{t}^{*}$ increases, will decrease real product wages if the labour supply elasticity is positive. The wage setting relation can be substituted into (2.7), (2.6), and (2.1) to obtain reduced form expressions for employment, hours per worker, and production. The first two are:

$$
\begin{gathered}
N_{t}=\Gamma_{1}^{*}\left(\rho \theta_{t}^{*} \tau_{t}^{*}\right)^{\frac{\lambda(\eta+1)}{\gamma}}, \\
H_{t}=\Gamma_{2}^{*}\left(\rho \theta_{t}^{*} \tau_{t}^{*}\right)^{\frac{\eta}{\gamma}} .
\end{gathered}
$$

The reduced forms for hours per worker and employment are, therefore, related in the following way:

$$
N_{t}=\Gamma_{3}^{*} H_{t}^{\lambda\left(1+\eta^{-1}\right)} .
$$

An exogenous change in labour productivity or taxes will move hours per worker and employment in the same direction if the labour supply elasticity is positive. There will be a negative relation iff $-1<\eta<0$.

\subsection{A stochastic version of the model}

Production and labour demand. In what follows we will consider the logarithms of the variables, denoting these by lower case letters. The stochastic production 
function has the following form:

$$
y_{t}=\theta_{t}+\delta h_{t}+\rho n_{t},
$$

where $\theta_{t}=\log \theta_{t}^{*}$ is the exogenous labour productivity variable. We assume that the differences between output growth and labour input growth, weighted by $\delta$ and $\rho$, are persistent in the sense:

$$
\theta_{t}=\theta_{t-1}+\varepsilon_{t, y}
$$

where $\varepsilon_{t, y}$ is a white noise innovation. This is by assumption a stochastic trend. The labour demand function, resting on the assumption that employment is the only choice variable for the firm when maximizing profits, is now written:

$$
n_{t}=\frac{1}{\rho-1}\left[w_{t}+h_{t}-\left(\log \rho+\theta_{t}+\delta h_{t}\right)\right]+\varepsilon_{t, n},
$$

where $\varepsilon_{t, n}$ is white noise. It follows that the logarithm of the wage share, given by:

$$
w s_{t} \equiv w_{t}+h_{t}+n_{t}-y_{t}=\log \rho+(1-\rho) \varepsilon_{t, n},
$$

is stationary. This is, in other words, by assumption a cointegrating relationship. Deviations from the wage share given by $\log \rho$ will follow the white noise innovation of labour demand.

Exogenous hours per worker. Suppose that hours per worker are exogenous with respect to the other variables of the model and evolve according to:

$$
\overline{h_{t}}=\pi \overline{h_{t-1}}+\varepsilon_{t, \bar{h}},
$$

where $\varepsilon_{t, \bar{h}}$ is white noise and $\pi \leq 1$. If $\pi=1$, hours per worker will follow a stochastic trend. This will be tested in the empirical analysis.

Wage setting. The stochastic wage setting relation is obtained by adding a wage shock $\omega_{t}$ to the logarithm of (2.4):

$$
w_{t}=\Gamma_{0}+\frac{1}{\gamma}\left(\log \rho+\theta_{t}\right)-\frac{\gamma-1}{\gamma} \tau_{t}-\frac{\gamma-\delta}{\gamma} \overline{h_{t}}+\omega_{t},
$$

where $\Gamma_{0}=\log \Gamma_{0}^{*}$ and $\eta=0$ in $\gamma$. The wage shock $\omega_{t}$ is specified as:

$$
\omega_{t}=\xi \omega_{t-1}+\varepsilon_{t, w},
$$

where $\varepsilon_{t, w}$ is a white noise innovation and $\xi \leq 1$. In the empirical analysis, we will test whether the wage shock follows a stochastic trend. It remains to specify 
how the tax wedge develops. We will assume that $\tau_{t}=\log \tau_{t}^{*}$ evolves according to:

$$
\tau_{t}=\varphi \tau_{t-1}+\varepsilon_{t, t},
$$

and where $\varepsilon_{t, t}$ is a white noise innovation and $\varphi \leq 1$. If $\varphi<1$ so that the wedge is not a stochastic trend. Solve (2.14) for $\left(\log \rho+\theta_{t}\right)$ and substitute:

$$
w_{t}=\frac{1}{\lambda} n_{t}-\overline{h_{t}}-\tau_{t}+\frac{1}{(\gamma-1)}\left[\gamma\left(\Gamma_{0}+\omega_{t}\right)-(1-\rho) \varepsilon_{t, n}\right] .
$$

Provided that the wedge $\tau_{t}$ is stationary $(\varphi \leq 1)$ and the wage shock also is stationary $(\xi<1)$ there will exist a cointegrating relation in $w_{t}, \overline{h_{t}}$, and $n_{t}$ such that $\lambda\left(w_{t}+\overline{h_{t}}\right)-n_{t}$ is stationary.

Endogenous labour supply. The stochastic form of the labour supply function (2.6) is:

$$
h_{t}=\eta\left(\tau_{t}+w_{t}\right),
$$

where $\tau_{t}$ evolves according to (2.19). Suppose that $\varphi<1$ so that the wedge is not a stochastic trend. Then it follows that there is a cointegrating relationship between hours per worker and the real wage, $h_{t}-\eta w_{t}$ will be stationary. This will be tested in the empirical analysis.

Wage setting. In this case, the stochastic wage setting relation is obtained by adding a wage shock $\omega_{t}$ to the logarithm of (2.8):

$$
w_{t}=\Gamma_{0}+\frac{1}{\gamma}\left(\log \rho+\theta_{t}\right)-\frac{\gamma-1}{\gamma} \tau_{t}+\omega_{t},
$$

where the wage shock $\omega_{t}$ follows (2.18). Solving (2.14) and (2.21) for $\left(\log \rho+\theta_{t}\right)$ and $\tau_{t}$, respectively, and substituting into (2.22) yields a cointegrating relation in $h_{t}$ and $n_{t}$, if $\xi<1$. The relation is:

$$
n_{t}=\lambda\left(1+\eta^{-1}\right) h_{t}+\varepsilon_{t, n}+\frac{1}{\rho-1}\left[\gamma \Gamma_{0}+\omega_{t}\right]
$$

Hence $n_{t}-\lambda\left(1+\eta^{-1}\right) h_{t}$ is stationary. Moreover, if $\varphi<1$ in the labour supply function in (2.21), combining yields $\lambda(\eta+1) w_{t}-n_{t}$. Note that if the wage chock is integrated $(\xi=1)$, so that wages increase over time (for given labour productivity and taxes), employment will be decreasing.

\subsection{Summary}

The implications regarding integration-cointegration properties of the stochastic model will now be summarized. The model allows for one, two, or possibly three stationary or cointegrating relations between the four variables. This is easily 
understood recalling the result that the number of cointegrating relations is given by the dimensionality of the system minus the number of stochastic trends driving the system, see King et al. (1991).

If the trend associated with the labour productivity variable in (2.13) is the sole trend (this means that $\varphi$ in (2.19) and $\xi$ in (2.18) are less than unity) then the model involves three cointegrating relations. One is given by the wage share in (2.15). If hours per worker are endogenous with respect to the other variables in the model, a second relation is given by $h_{t}-\eta w_{t}$, and a third given by $n_{t}-$ $\lambda\left(1+\eta^{-1}\right) h_{t}$. The second and the third relations can be combined to give the long-run relationship between real wages and employment, $\lambda(\eta+1) w_{t}-n_{t}$.

If instead hours per worker are exogenous with respect to the other variables, the wage share will remain stationary. A second cointegrating relation is given by $\lambda\left(w_{t}+\overline{h_{t}}\right)-n_{t}$. But which is the third? If labour productivity is the only trend then hours per worker must be stationary. In other words, the third relation is simply $\overline{h_{t}}$ itself. This, in turn simplifies the second relation to $\lambda w_{t}-n_{t}$.

Suppose that hours per worker is a non-stationary variable. If $\overline{h_{t}}$ is exogenous, there will, at most, two cointegrating relations. If either the tax wedge or the wage shock is non-stationary there will only exist on relation - the wage share. On the other hand, if $\overline{h_{t}}$ is endogenous there could exist three cointegrating relations. If the tax wedge is not stationary, there will be one relation less. If the wage shock is non-stationary there will also be one relation less.

\section{Empirical analysis}

In the first part of this section we are concerned with the cointegration properties of the private sector model. Specifically, we will establish whether the theoretical model in the previous section is consistent with data, and if it is appropriate to model one, two, or three common stochastic trends. The latter is, as is well known, equivalent with a test for the number of cointegrating relationships, or steady states. Moreover, we will examine if the cointegrating relations, e.g., the wage share, suggested by the theoretical model are reasonable representations in the empirical model.

Let $X_{t}$ be an endogenous vector time series in $m$ dimensions and $D_{t}$ a vector of centred seasonal dummies. A vector autoregressive representation for $X_{t}$ with exogenous variables is written

$$
X_{t}=\mu+\Psi D_{t}+\sum_{j=1}^{p} \Pi_{j} X_{t-j}+\varepsilon_{t}, \quad t=1,2, \ldots, T .
$$

We assume that $p$ is the appropriate order of the lag polynomial. Also, we assume 
that $X_{t}$ is first-difference stationary, but possibly non-stationary in levels. Finally, the error term $\varepsilon_{t}$ is assumed to be iid $N(0, \Sigma)$.

A slight reparametrization of (3.1) yields a multivariate error correction representation suitable for estimation and statistical analysis of the cointegrating vectors by means of maximum likelihood (see Johansen (1991, 1992a) and Johansen and Juselius (1990, 1992) for details).

$$
\Delta X_{t}=\mu+\Psi D_{t}+\sum_{i=1}^{p-1} \Gamma_{i} \Delta X_{t-i}-\alpha \beta^{\prime} X_{t-p}+\varepsilon_{t},
$$

where $\Gamma_{i}=\sum_{j=i+1}^{p} \Pi_{j}$ and $\alpha \beta^{\prime}=\Pi=I_{m}-\sum_{j=1}^{p} \Pi_{j}$. The latter reflects the cointegrating reduced rank assumption for $\Pi ; r<m$, and hence $\alpha$ and $\beta$ are matrices of order $(m \times r)$. Johansen (1991) has shown under what conditions $\beta^{\prime} X_{t}$ and $\Delta X_{t}$ are stationary for a non-stationary $X_{t} . X_{t}$ is said to be cointegrated for $r>0$ and the cointegrating vectors are given by the $r$ columns of $\beta$. The $r$ rows of $\alpha$ contain the elements that determine how the cointegrating relations $\beta^{\prime} X_{t}$ enter the $m$ equations of (3.2). In the empirical analysis we take $X_{t}^{\prime}=$ $\left[\begin{array}{llll}y_{t} & w_{t} & h_{t} & n_{t}\end{array}\right]$.

Estimation of (3.2) requires determination of the lag order $p .{ }^{5}$ To this end we estimate the model for orders 1 to 8 and examine the resulting residual sets. The test results suggest $p=4$ as a reasonable order, see Table 3.1. The two multivariate information criteria, the Bayesian information criteria (BIC; Schwarz (1978)) and the iterated log-criterion (LIL; Hannan and Quinn (1979)), are minimized for $p=4$. For this lag order we find that the multivariate Portmanteau test with a Box-Ljung correction, cf. Ljung and Box (1978) and Hosking (1980), rejects the null of no serial correlation using a test size of $1 \%$. However, the two Lagrange multiplier tests, $\operatorname{LM}(1)$ and $\operatorname{LM}(4)$, for first and fourth order serial correlation, suggested in Godfrey (1988), are insignificant. Finally, multivariate normality is evaluated using an omnibus test based on estimated skewness and kurtosis as suggested by Doornik and Hansen (1994). The hypothesis of normality cannot be rejected at any reasonable level. Table 3.2 presents univariate residual analysis for model (3.2) with results that confirm the appropriateness of setting $p=4$.

It is also useful to calculate the roots, $\widehat{z}$, of the estimated polynomial equations $\operatorname{det}\left[I_{4}-\sum_{1}^{p} \widehat{\Pi}_{j} z^{j}\right]=0$. We find that all estimated roots have modulus greater than unity (implying stationarity). However one root is very close to the unit circle. This can be interpreted as informal support for the unit root modelling approach.

Table 3.3 presents the outcome of the likelihood ratio test for cointegrating rank, known as the trace test. The testing strategy is sequential, for details see

\footnotetext{
${ }^{5}$ We have used the CATS IN RATS software, see Hansen and Juselius (1995).
} 
Table 3.1: Lag order determination and multivariate residual analysis for the Swedish labor market model, $p$-values within parentheses.

\begin{tabular}{|ccccccc|}
\hline$p$ & BIC & LIL & Box-Ljung & LM(1) & LM(4) & Normality \\
& & & & & & \\
1 & -30.4436 & -31.2107 & 574.436 & 39.943 & 89.219 & 18.296 \\
& & & $(.00000)$ & $(.00079)$ & $(.00000)$ & $(.01911)$ \\
2 & -30.2627 & -31.3167 & 448.957 & 27.872 & 69.068 & 20.035 \\
& & & $(.00000)$ & $(.03275)$ & $(.00000)$ & $(.01020)$ \\
3 & -30.5258 & -31.8711 & 406.867 & 49.550 & 31.861 & 23.179 \\
& & & $(.00000)$ & $(.00003)$ & $(.01042)$ & $(.00314)$ \\
4 & -30.9344 & -32.5755 & 325.350 & 27.623 & 15.157 & 8.965 \\
& & & $(.00216)$ & $(.03506)$ & $(.51317)$ & $(.34526)$ \\
5 & -30.5157 & -32.4572 & 288.247 & 16.270 & 23.590 & 13.642 \\
& & & $(.00243)$ & $(.43428)$ & $(.09895)$ & $(.09159)$ \\
6 & -29.937 & -32.1840 & 300.016 & 20.242 & 23.341 & 8.398 \\
& & & $(.00003)$ & $(.20952)$ & $(.10492)$ & $(.39559)$ \\
7 & -29.341 & -31.8982 & 298.285 & 25.501 & 15.924 & 7.953 \\
& & & $(.00000)$ & $(.06147)$ & $(.45828)$ & $(.43807)$ \\
8 & -29.2180 & -32.0901 & 267.079 & 17.702 & 14.434 & 9.983 \\
& & & $(.00001)$ & $(.34163)$ & $(.56642)$ & $(.26622)$ \\
\hline
\end{tabular}

Table 3.2: Univariate residual analysis for the Swedish labor market model.

\begin{tabular}{|cccccc|}
\hline Equation & Skewness & Kurtosis & ARCH & Normality & $R^{2}$ \\
& & & & & \\
$y_{t}$ & .2654 & \multirow{2}{*}{3.3453} & 2.445 & 2.006 & .981 \\
& & & $(.6545)$ & $(.3668)$ & \\
$w_{t}$ & .1461 & 2.8759 & 2.391 & 0.375 & .967 \\
& & & $(.3026)$ & $(.8290)$ & \\
$h_{t}$ & .0910 & \multirow{2}{*}{3.3058} & 9.592 & 1.554 & .997 \\
& & & $(.0492)$ & $(.4598)$ & \\
$n_{t}$ & -.2407 & 2.6593 & 7.749 & 1.128 & .889 \\
& & & $(.1012)$ & $(.5689)$ & \\
\hline
\end{tabular}


Table 3.3: Likelihood ratio testing for cointegrating rank in the Swedish labor market model.

\begin{tabular}{ccccc}
\hline$H_{0}$ & $L R_{\text {trace }}$ & .90 & .95 & .99 \\
\hline$r=0$ & 97.10 & 43.95 & 47.21 & 54.46 \\
$r \leq 1$ & 44.14 & 29.79 & 29.68 & 35.65 \\
$r \leq 2$ & 22.25 & 13.33 & 15.41 & 20.04 \\
$r \leq 3$ & 4.10 & 2.64 & 3.65 & 6.65 \\
\hline
\end{tabular}

Johansen (1992a), so first we consider a null of no cointegration $(r=0)$ against the alternative of at least one cointegrating vector $(1 \leq r \leq 4)$. The observed value is 97.10 and clearly this exceeds the $1 \%$ asymptotic critical value (54.46). Next we consider the null of no more than one vector $(r \leq 1)$ against the alternative of at least two vectors $(2 \leq r \leq 4)$. The observed value is 44.14 and the null is again rejected. Likewise the next null $(r \leq 2)$ is rejected, but we cannot reject the last null without increasing the test size in use. The conclusion drawn is that three cointegrating vectors are at hand. As pointed out earlier, this result implies that one common stochastic trend is driving the system and, in light of the theoretical model, we interpret this trend as a labour productivity variable, cf. equation 2.13.

When summarizing the theoretical model, we considered two cases of hours per worker; as an exogenous variable with respect to the system, and as an endogenous variable in the system. It was found that an assumption of exogeneity for hours per worker reduced the cointegrating rank to 2, whereas endogenous hours implied three cointegrating vectors. The outcome of the trace test, $\mathrm{r}=3$, is hence consistent with an assumption of endogenous hours per worker. Moreover, as can be seen in Table 3.4, the test for weak exogeneity of $\Delta h_{t}$ with respect to $\alpha$ and $\beta$ must be firmly rejected. ${ }^{6}$

The three estimated cointegrating vectors are:

$$
\widehat{\beta}^{\prime}=\left[\begin{array}{rrrr}
-1.43 & 4.74 & 38.59 & 22.26 \\
-14.63 & 18.30 & 58.35 & -76.85 \\
14.74 & -5.01 & 27.25 & -20.50
\end{array}\right] \text {. }
$$

By imposing restrictions on $\widehat{\beta}$ we can now test, by likelihood ratio, if the three

\footnotetext{
${ }^{6}$ The likelihood ratio test for linear restrictions on cointegrating vectors is known to be oversized in finite samples, see, e.g., Jacobson et al. (1996). But considering the magnitude of the statistic in this case, 44.38, the rejection result is likely to be robust towards such size distortion.
} 
Table 3.4: Likelihood ratio testing of restrictions on the long-run parameters $\alpha$ and $\beta$ for given cointegrating rank, $\mathrm{r}=3$.

\begin{tabular}{|c|c|c|c|}
\hline Equation & Exclusion & Stationarity & Weak exogeneity \\
\hline$y_{t}$ & $\begin{array}{c}15.01 \\
(.00181)\end{array}$ & $\begin{array}{c}6.03 \\
(.01407)\end{array}$ & $\begin{array}{c}19.46 \\
(.00022)\end{array}$ \\
\hline$w_{t}$ & $\begin{array}{c}11.31 \\
(.01016)\end{array}$ & $\begin{array}{c}13.60 \\
(.00023)\end{array}$ & $\begin{array}{c}15.53 \\
(.00142)\end{array}$ \\
\hline$h_{t}$ & $\begin{array}{c}23.99 \\
(.00003)\end{array}$ & $\begin{array}{c}8.17 \\
(.00426)\end{array}$ & $\begin{array}{c}44.38 \\
(.00000)\end{array}$ \\
\hline$n_{t}$ & $\begin{array}{c}20.25 \\
(.00015)\end{array}$ & $\begin{array}{c}1.10 \\
(.29427)\end{array}$ & $\begin{array}{c}12.62 \\
(.00554)\end{array}$ \\
\hline \multicolumn{4}{|c|}{$\begin{array}{l}\text { Remark: Details of the testing procedures for linear restrictions } \\
\text { of } \alpha \text { and } \beta \text { are provided in Johansen (1991) and Johansen and } \\
\text { Juselius (1992). The exclusion test (the element associated with } \\
\text { a given variable is zero in all three vectors) is asymptotically } \\
\chi^{2}(3) \text {. The test for weak exogeneity is also } \chi^{2}(3) \text { whereas the } \\
\text { stationarity test is asymptotically } \chi^{2}(1) \text {. }\end{array}$} \\
\hline
\end{tabular}

theoretical vectors suggested by the model in Section 2 are in fact contained in the estimated cointegrating space, cf. Johansen and Juselius (1994). That is, we will test if : $w_{t}+h_{t}+n_{t}-y_{t}, h_{t}-\eta w_{t}$, and the third relation given by $n_{t}-\lambda\left(1+\eta^{-1}\right) h_{t}$, can be empirically verified. The latter two relations can be obtained by a simply normalizing the vectors suitably, whereas the wage share involves a genuine restriction. The test statistic is 3.74 and asymptotically $\chi^{2}$ with 1 degree of freedom. The associated $p$-value is slightly larger than .05 and hence we do not reject the hypothesis. The restricted cointegrating vectors are:

$$
\widehat{\beta}_{R}^{\prime}=\left[\begin{array}{rrrr}
-1 & 1 & 1 & 1 \\
0 & 0.103 & 1 & 0 \\
0 & 0 & -0.0183 & 1
\end{array}\right]
$$

Solving for the two parameters involved $\eta$ and $\lambda$, we find the estimates to be: $\widehat{\eta}=-0.103$ and $\widehat{\lambda}=-0.00210$. The estimated preference parameter in the labour supply equation (2.6) suggesting the income effect dominates the substitution effects. The estimated union preference parameter in the union wage setting equation (2.3) is clearly at odds with the assumption $0<\lambda<1$. However, the standard error associated with $\lambda\left(\widehat{1+\eta^{-1}}\right)$ is 0.079 . This implies that employment 
in itself is a stationary variable as $\lambda\left(\widehat{1+\eta^{-1}}\right)$ is not significantly different from zero. If employment is stationary while hours per worker is not there is, of course, no long-run relationship between the two variables.

We can also compute an estimate of $\log \rho$ by calculating the mean of log wage share. The estimate is $\widehat{\log \rho}=-0.382$. This suggests a value of $\rho=0.682$ with a standard error of 0.026 . For those who find this mean of the wage share low, it should be stressed that we only include wage income of employed, while selfemployed are not included.

\section{Extension: Introducing standard hours}

Suppose that the labour supply is stochastic and is related to legislated working time, which we will call standard hours. Then we can write:

$$
h_{t}=h s_{t}+\nu_{t}
$$

where $h s_{t}$ represent standard hours and $\nu_{t}$, the difference between actual hours and standard hours, evolves according to:

$$
\nu_{t}=\kappa \nu_{t-1}+\varepsilon_{t, h}
$$

where $\varepsilon_{t, h}$ is a white noise innovation and $\kappa \leq 1$. Differences between actual hours per worker and standard hours may arise because, e.g., overtime, temporary layoffs, and part-time work. Suppose that $\kappa<1$ then the deviations of actual hours from standard hours are stationary.

Figure 4.1 displays two hours per worker series, actual and standard, over the sample period 1963:1-1993:4. Two features can be noted. First, the two series are linked together, suggesting a cointegrating relationship such that one minus the other is a stationary variable $(\kappa<1)$. Second, standard hours, considering its step-function appearance, can hardly be modelled as an endogenous, non-stationary variable in the empirical maximum likelihood cointegration model. Moreover, for the investigation period at hand, 1970:1-1990:4, standard hours are almost constant, and hence not suitable to include in the empirical model even as an exogenous, non-stationary variable.

However, a small bivariate system comprising actual and standard hours per worker is suitable for examining the cointegration issue, i.e. we propose to fit model (3.2) with $X_{t}^{\prime}=\left[h_{t} h s_{t}\right]$, over the extended sample period 1963:1-1993:4. Indeed we find that the equation for actual hours per worker is misspecified for any reasonable lag-order $p$. By treating $h s_{t}$ as weakly exogenous for the estimation of the long run parameters $\alpha$ and $\beta$, we reduce the VAR model to a single-equation model for $\Delta h_{t}{ }^{7}$

\footnotetext{
${ }^{7}$ For a theoretical background of conditional, cointegrated VAR models see Johansen (1992b).
} 
Figure 4.1: Actual and standard hours per worker, logarithms, seasonally adjusted deviations from the mean of actual hours per worker.

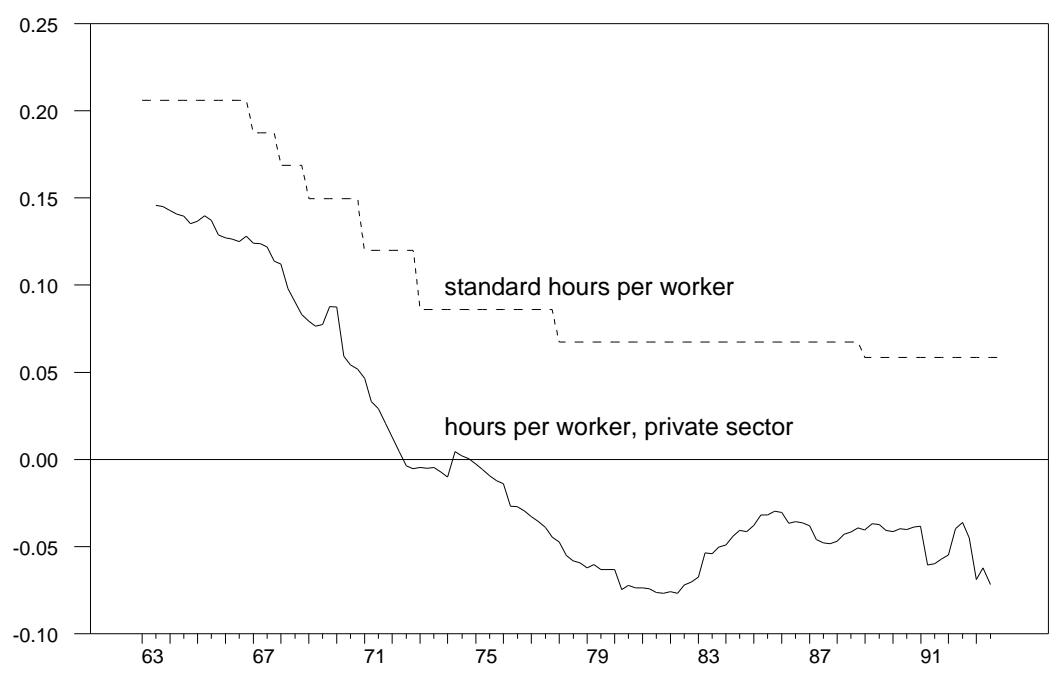

The single-equation model with for $p=4$ lags imposed is statistically well specified in terms of residuals. The estimated trace test statistic for cointegrating rank is 7.18. It is reasonable to conclude a rejection of the null hypothesis that the cointegrating rank is zero, even though, strictly speaking, the $5 \%$ critical value 3.65 is incorrect for the specified model. The estimated cointegrating vector, normalized with respect to $h_{t}$, is $\left[\begin{array}{ll}1 & -1.147\end{array}\right]$ confirming the visual impression. A likelihood ratio test of the linear restriction implied by the hypothesis $h_{t}-h s_{t} \sim$ $I(0)$ yields a test statistic of 0.49 which is asymptotically $\chi^{2}$ with one degree of freedom and hence insignificant. We conclude that actual and standard hours are cointegrated.

\section{Concluding discussion}

The objective of the paper is to study three necessary conditions for work sharing to increase employment. First, there must exist a negative long-run relation between working time and employment. Second, hours per worker must be exogenous with respect to wages and employment. Third, policy makers must be able to influence actual working time. We formulate a theoretical labour market model with employment, hours per worker, production, and real wages as endogenous variables. The stochastic specification implies an integrated system allowing for at least one, possibly two or three cointegrating relationships, with the dual result 
of three, two, or one common stochastic trends driving the variables. A cointegrated VAR system is estimated by maximum likelihood using Swedish private sector data 1970:1-1990:4.

We have three main findings for work sharing. First, we do not find evidence of a negative long-run trade-off between employment and hours per worker. Employment is found to be stationary whilst hours per worker are not. Second, the data are consistent with hours per worker being endogenous with respect to employment, production, and real wages. Third, we do find that legislated hours per worker are cointegrated with actual hours per worker. Taken together, the results are not consistent with the claims that work sharing can promote employment.

In addition, we find that the wage share is stationary as predicted by the theoretical model. Furthermore, there is evidence of a negative long-run relationship between real wages and hours per worker. This suggests that income effects may be as important for labour supply as substitution effects. 


\section{References}

Doornik, J.A. and Hansen, H. (1994). An omnibus test for univariate and multivariate normality, Working Paper, Nuffield College, Oxford.

Freeman, R. (1995). The Large Welfare State as a System. American Economic Review Papers and Proceedings, 85, 16-21.

Godfrey, L.G. (1988). Misspecification tests in Econometrics. The Lagrange Multiplier principle and other approaches, Cambridge University Press.

Hannan, E.J. and Quinn, B.G. (1979). The determination of an order of an autoregression, Journal of the Royal Statistical Society, Series B, 41, 190195.

Hansen, H. and Juselius, K. (1995). CATS in RATS. Cointegrating Analysis of Time Series, Estima, Evanston, IL.

Hosking, J.R.M. (1980). The Multivariate Portmanteau Statistic, Journal of the American Statistical Society, 75, 602-608.

Houpis, G. (1993). The effect of lower hours of work on wages and employment, Discussion Paper No. 131, Centre for Economic Performance.

Jacobson, T., Vredin, A. and Warne, A. (1996). Common Trends and Hysteresis in Scandinavian Unemployment, European Economic Reviewt, forthcoming.

Johansen, S. (1991). Estimation and hypothesis testing of cointegration vectors in Gaussian vector autoregressive models, Econometrica, 59, 1551-1580.

Johansen, S. (1992a). Determination of the Cointegrating Rank in the Presence of a Linear Trend, Oxford Bulletin of Economics and Statistics, 54, 383-397.

Johansen, S (1992b). Cointegration in Partial Systems and the Efficiency of Single Equation Analysis, Journal of Econometrics 52, 389-402.

Johansen, S. and Juselius, K. (1990). Maximum likelihood estimation and inference on cointegration - with applications to the demand for money, Oxford Bulletin of Economics and Statistics, 52, 169-210.

Johansen, S. and Juselius, K. (1992). Testing Structural Hypotheses in a Multivariate Cointegration Analysis of the PPP and the UIP for U.K., Journal of Econometrics, 53, 211-244. 
Johansen, S. and Juselius, K. (1994). Identification of the long-run and the shortrun structure: An application to the ISLM model, Journal of Econometrics, 63, $7-36$.

King, R.G., Plosser, C.I., Stock, J.H., and Watson, M.W. (1991). Stochastic Trends and Economic Fluctuations, American Economic Review, 81, 819840.

Kydland, F.E. (1995). Business Cycles and Aggregate Labor Market Fluctuations, in Cooley, T.F. (ed.), Frontiers of Business Cycle Research, Princeton University Press, Princeton, NJ.

Ljung, G.M. and Box, G.E.P. (1978). On a measure of lack of fit in time series models, Biometrika, 66, 265-270.

Nilsson, C. (1993). The Swedish Model: Labour Market Institutions and Contracts, in Hartoug, J. and Theeuwes, J. (eds.), Labour Market Contracts and Institutions, Elsevier, Amsterdam.

Schwarz, G. (1978), Estimating the dimension of a model, Annals of Statistics, 6, 461-464.

Whitley, J.D. and Wilson, R.A. (1988). Hours Reductions within Large-scale Macroeconomic Models: Conflict between Theory and Empirical Application, in Hart, A.A. (ed.), Employment, Unemployment and Labour Utilisation, Unwin Hyman, MA. 


\section{Appendix A Union utility}

Suppose that the expected union utility of the income of a representative union member is

$$
U_{t}=\frac{N_{t}}{L F_{t}}\left(\tau_{t}^{*} W_{t} H_{t}\right)^{\lambda}+\left(1-\frac{N_{t}}{L F_{t}}\right) r_{t}^{\lambda} .
$$

where $r_{t}^{\lambda}$ is the utility when unemployed. This can rewritten to

$$
\begin{aligned}
& U_{t}=\left(\tau_{t}^{*} W_{t} H_{t}\right)^{\lambda}-\left(1-\frac{N_{t}}{L F_{t}}\right)\left(\left(\tau_{t}^{*} W_{t} H_{t}\right)^{\lambda}-r_{t}^{\lambda}\right) \\
& =\left(\tau_{t}^{*} W_{t} H_{t}\right)^{\lambda}+\left(N_{t}-L F_{t}\right)\left(\left(\tau_{t}^{*} W_{t} H_{t}\right)^{\lambda}-r_{t}^{\lambda}\right) \frac{1}{L F_{t}}
\end{aligned}
$$

Suppose that excess utility when employed, compared to being unemployed, grows with the same rate as the labour force, then the appropriate choice of units will yield

$$
U_{t}=\left(\tau_{t}^{*} W_{t} H_{t}\right)^{\lambda}+N_{t}-L F_{t}
$$

which is equation (2.3) in the main text.

\section{Appendix B The Data - sources and definitions}

The data are for the private sector in Sweden during the period 1970:1-1990:4. The four variables are:

\section{$Y_{t}$, real production}

We use the real private sector GDP at 1985 prices as measured from the expenditure side but excluding indirect taxes and subsidies. The sources are:

a. 1970:1 - 1979:4, Statistics Sweden, BNP Kvartal (Quarterly GDP) 1986:4.

b. 1980:1 - 1990:4, Statistics Sweden, BNP Kvartal (Quarterly GDP) 1992:4.

The data for the 1970 s are at 1980 prices. We have multiplied the data by a factor computed as

$$
\frac{(\text { annual GDP } 1980,1985 \text { prices according to } b)}{(\text { annual GDP } 1980,1980 \text { prices according to } a)}
$$

\section{$W_{t}$, real hourly wages}

Real hourly wages in the private sector have been computed as

$$
\frac{[(\text { nominal wages } / \text { hours worked }) *(1+\text { payroll taxes })]}{\text { producers price index }} .
$$


The sources for nominal wages are

a. 1970:1 - 1980:4, Statistics Sweden, unpublished tables.

b. 1980:1 - 1990:4, Statistics Sweden, unpublished tables.

The sources for hours worked are

a. 1970:1 - 1980:4, Statistics Sweden, unpublished tables.

b. 1980:1 - 1990:4, Statistics Sweden, BNP Kvartal (Quarterly GDP) 1992:4.

There is a difference between $a$ and $b$ in (nominal wages/hours worked) in 1980 .

We have multiplied the data for the 1970s by a factor

$$
\frac{\text { sum of (nominal wages/hours worked) 1980:1-1980:4 according to } b}{\text { sum of (nominal wages/hours worked) 1980:1-1980:4 according to } a} \text {. }
$$

The source for payroll taxes is SAF, Fakta om Sveriges skatter. The data are annual averages.

The producers price index on quarterly basis for the entire period is only available for manufacturing. We therefore use the manufacturing index as a proxy for the whole private sector. The sources are

a. 1970:1 - 1972:3, Statistics Sweden, Allmän månadsstatistik, various issues.

b. 1972:4 - 1990:4, Statistics Sweden, Allmän månadsstatistik, various issues.

The data for the first years have the base $1963=100$ while the other data have the base $1968=100$. Using monthly data for 1968 with base $1963=100$ we compute the chain factor to 1.1133. The data from $a$. are divided by this factor.

\section{$N_{t}$, employment}

The data for private employment (not including self-employed) are from the quarterly labour force surveys. Because of a labour market dispute there is no survey available for the second quarter of 1980 . We have imputed a value computed as the mean of corresponding quarters in 1979 and 1981.

\section{$H_{t}$, hours per worker}

Hours per worker in the private sector is computed as

$$
\frac{\text { (total hours worked by employees) }}{\text { (number of employees) }} \text {. }
$$

The data are from the quarterly labour force surveys.

\section{$H S_{t}$, legislated maximum hours per worker}

Standard hours have been computed combining legislated weekly working time, number of paid vacation days, and holidays. The source is Nilsson (1993). 